\title{
Land subsidence of clay deposits after the Tohoku-Pacific Ocean Earthquake
}

\author{
K. Yasuhara ${ }^{1}$ and M. Kazama ${ }^{2}$ \\ ${ }^{1}$ Institute for Global Change Adaptation Science, Ibaraki University, 2-1-1 Bunkyo, Mito, \\ Ibaraki, 310-8512, Japan \\ ${ }^{2}$ Graduate School of Engineering, Tohoku University, 2-1-1 Katahira Aoba-ku Sendai-shi, \\ Miyagi, 980-8577, Japan \\ Correspondence to: K. Yasuhara (kazuya.yasuhara.0927@vc.ibaraki.ac.jp) \\ Published: 12 November 2015
}

\begin{abstract}
Extensive infrastructure collapse resulted from the cataclysmic earthquake that struck off the eastern coast of Japan on 11 March 2011 and from its consequent gigantic tsunami, affecting not only the Tohoku region but also the Kanto region. Among the geological and geotechnical processes observed, land subsidence occurring in both coastal and inland areas and from Tohoku to Kanto is an extremely important issue that must be examined carefully. This land subsidence is classifiable into three categories: (i) land sinking along the coastal areas because of tectonic movements, (ii) settlement of sandy deposits followed by liquefaction, and (iii) longterm post-earthquake recompression settlement in soft clay caused by dissipation of excess pore pressure. This paper describes two case histories of post-earthquake settlement of clay deposits from among the three categories of ground sinking and land subsidence because such settlement has been frequently overlooked in numerous earlier earthquakes. Particularly, an attempt is made to propose a methodology for predicting such settlement and for formulating remedial or responsive measures to mitigate damage from such settlement.
\end{abstract}

\section{Introduction}

Land subsidence and ground sinking are as remarkable and extremely severe phenomena as the gigantic tsunami that struck Tohoku and Kanto in Japan after the 2011 Off the Pacific Coast of Tohoku Earthquake (hereinafter the "Tohoku Earthquake"). Moreover, the mechanisms of both events are extremely complex because several factors induced land subsidence and ground sinking from tectonic, geologic, and geotechnical aspects, exerting overlapping influences that persist even now, four years after the earthquake.

Roughly speaking, this land subsidence and ground sinking is classifiable into three categories: (i) land sinking along coastal areas because of tectonic movements (Imakiire and Koarai, 2012, Yasuhara et al., 2012; (ii) settlement of sandy deposits followed by liquefaction, and (iii) long-term postearthquake recompression settlement in soft clays caused by the dissipation of excess pore pressure. Land sinking described in category (i) induces inundation of wide coastal areas, particularly during severe storm-surges and strong ty- phoons. However, land subsidence in the latter two categories (ii) and (iii) occurs in inland areas, strongly influencing local residents. A difference is apparent between the mechanisms of settlement of both types in that settlement included in category (ii) is related to saturated sandy deposits, whereas settlement in category (iii) is associated with saturated clayey deposits, which cause them to take a long time to cease. Based on differences among the causes and mechanisms related to the three kinds of land subsidence described above, suitable countermeasures against subsidence should be taken, corresponding to their different characteristics.

This paper presents two case histories of post-earthquake settlement of clay deposits from among the three categories of ground sinking and land subsidence described above because normally such settlement has been overlooked in numerous historical earthquakes. 


\section{Post-earthquake settlement of cohesive soil deposits in Miyagi}

Generally speaking, liquefaction-induced settlement described in the previous section ceases in a very short time. As described later, post-earthquake long-term settlement is caused mainly by consolidation of clayey soils situated under sand deposits simply because the hydraulic conductivity of clay layers is much lower than that of sand deposits. For that reason, a long time is necessary for the dissipation of excess pore pressure generated during earthquakes (Yasuhara et al., 2001; Yasuhara and Matsuda, 2002; Matsuda et al., 2014).

Figure 1 depicts the variations of settlement at bench marks after 1974, when the total amount of settlement was greater than $200 \mathrm{~mm}$ up to 2010 . Settlement measuring locations are benchmarks located in the eastern part of Sendai on the Quaternary alluvial lower plain of unconsolidated layers of around $50 \mathrm{~m}$. It is apparent from Fig. 1 that a sudden increase of settlement occurred after the 1978 Miyagioki Earthquake. It then progressed at a higher rate of settlement than before the earthquake. The sudden increase of settlement in 1978 resulted from the collapse of clay soil particle structures: an immediate effect of the earthquake action.

Acceleration of post-earthquake settlement as shown in Fig. 1 originated from the superimposition of land subsidence before the earthquake and consolidation settlement caused by the dissipation of excess pore pressure generated during the earthquake.

Figure 2 depicts an example of variations of settlement over time before and after the Tohoku Earthquake in 2011. The tendency presented in Fig. 2 is almost identical as that presented previously in Fig. 1.

Kazama (2014) reported that post-earthquake settlement of clay deposits are caused by collapse of clay soil particle structures immediately after the earthquake and the recovery of collapsed structures to the new state of clay structures This mechanism for post-earthquake settlement of clay soils is understood from Fig. 3, which portrays the progress of settlement in the form of void ratio, $e$ vs. logarithmic of vertical stress, $\log p$. To validate the proposed concept for estimating post-earthquake settlement, undrained cyclic triaxial tests followed by drainage were conducted by Kazama using undisturbed and remolded clay specimens taken from the site where settlement had taken place. Subsequently, the results from undrained cyclic triaxial tests followed by drainage under the conditions of 0.4 for cyclic stress ratio and $0.2 \mathrm{~Hz}$. for cyclic frequency are presented for comparison in Fig. 3 along with results from odometer tests on the undisturbed and remolded specimens of the same clay as that used in cyclic triaxial tests.

Void ratios after termination of undrained cyclic triaxial tests followed by drainage are shown on the vertical line corresponding to the consolidation pressure with $e-\log p^{\prime}$ curves in Fig. 3. Three dotted circles are shown after each

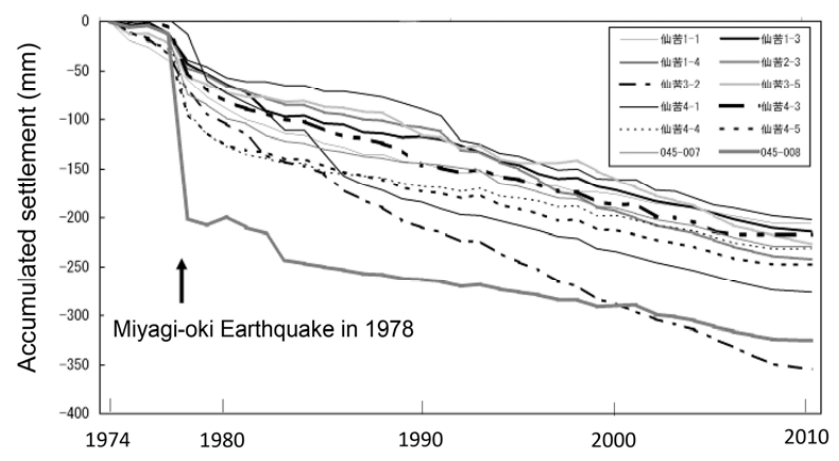

Figure 1. Examples of land subsidence variation in Sendai before and after the earthquake.

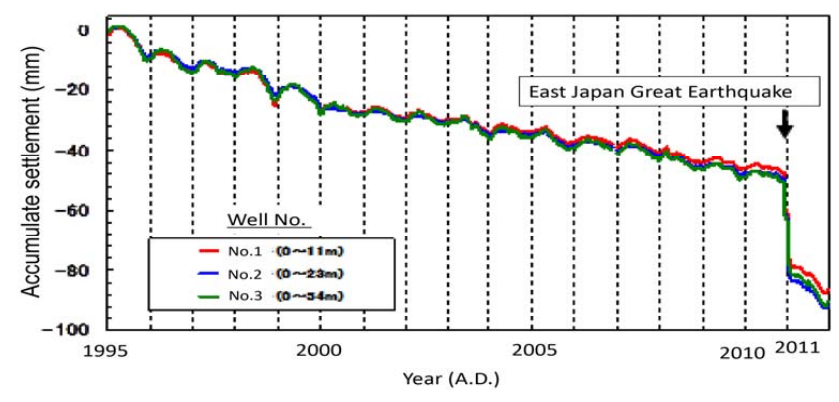

Figure 2. Variation of settlement before and after the Tohoku Earthquake (at Kamomachi of Sendai).

undrained loading followed by drainage, which simulates the circumstances under which three earthquakes struck separately after some intervals.

If initial void ratios under a current consolidation pressure $p_{i}^{\prime}$ for undisturbed and remolded conditions corresponds to cases before and after the earthquakes are assumed as $e_{i, \mathrm{u}}$ and $e_{\mathrm{f}, \mathrm{r}}$, respectively, then post-earthquake settlement $S_{\text {post }}$ is given as

$S_{\mathrm{post}}=\frac{e_{i, \mathrm{u}}-e_{\mathrm{f}, \mathrm{r}}}{1+e_{i, \mathrm{u}}} H$

where $H$ stands for the clay layer height. If one assumes 2.15 and 1.85 for $e_{i, \mathrm{u}}$ and $e_{\mathrm{f}, \mathrm{r}}$, respectively, and $10 \mathrm{~m}$ for the clay layer height, then one obtains $47.6 \mathrm{~cm}$ for post-earthquake settlement $S_{\text {post }}$.

Another methodology can be used to estimate the postearthquake settlement of clay layers proposed by Yasuhara et al. (1991, 2001). It is given as

$S_{\mathrm{post}}=0.225 C_{c} H \log \left(\frac{1}{1-\frac{u_{\mathrm{cy}}}{p_{c}^{\prime}}}\right)$,

where $C_{c}$ stands for the compression index of clay soil, $H$ signifies the clay layer height, $u_{\mathrm{cy}}$ represents excess pore pressure generated by the earthquake, and $p_{c}^{\prime}$ denotes the consolidation or overburden pressure. When we take values 


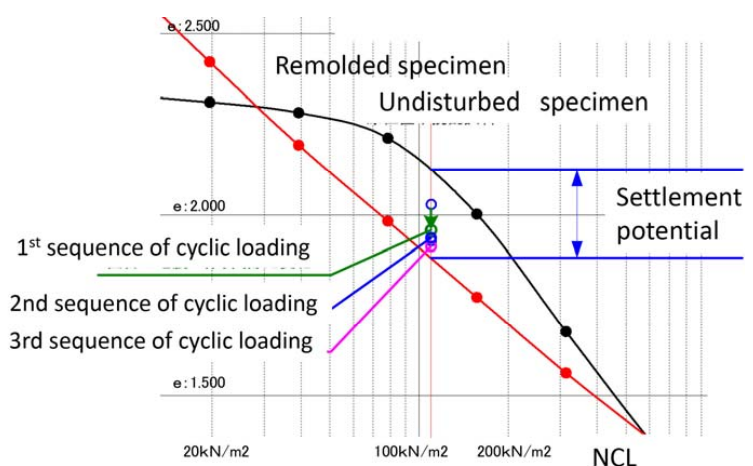

Figure 3. Void ratio vs. consolidation pressure relations for prediction of post-earthquake settlement of clay deposits (from Kazama, 2014).

from Fig. xx for $C_{c}, H, u_{\mathrm{cy}}$ and $p_{c}^{\prime}$ as $1.06,5.0 \mathrm{~m}, 0.5 p_{c}^{\prime}$ and $110 \mathrm{kN} \mathrm{m}^{-2}$, then we obtain $33.9 \mathrm{~cm}$ for $S_{\text {post }}$. It is assumed here for calculation using Eq. (2) that the normalized excess pore pressure in the clay layer, $u_{\mathrm{cy}} / p_{c}^{\prime}$ is 0.5 . Therefore, the amount of settlement will be less than this value, 05 , when $u_{\text {cy }} / p^{\prime} c$ is smaller than 0.5 . The amount of settlement of $33.9 \mathrm{~cm}$ obtained using Eq. (2) is less than the $47.6 \mathrm{~cm}$ obtained using Eq. (1).

\section{Post-earthquake settlement of cohesive soil deposits in Ibaraki}

\subsection{Outlines of post-earthquake settlement of residential areas beside the River Dykes}

Another case study in Ibaraki is that where clay deposits near the river dyke have undergone post-earthquake settlement causing damage to many private residences. The horizontal profile of the river dyke and the residential areas portrayed in Fig. 4 indicate a thick clay layer with $\mathrm{xx} \mathrm{m}$ deposits on the sand layer with the higher ground water level (GWL). clay is characterized by the following. Highly sensitive with high liquidity index High water content with high undrained strength Post-earthquake settlement is expected to result from consolidation followed by dissipation of excess pore pressures generated by a strong earthquake. The average index properties of clay are presented in Table 1. This

Characteristic (ii) does not make sense from geotechnical perspective. It is extremely unusual although characteristic (i) does make sense. This clay has high structures of clay particles, which readily undergo deformation by disturbance, leading to radical deformation and settlement. For comparison with Kujikawa clay, Table 1 also includes index properties of Joban clay, deposited beneath the Kanda area of Joban express highway, which was constructed almost 35 years ago. Both clays are similar: both are highly plastic and become considerably soft with water contents beyond the liq-
Table 1. Index properties of clay beneath river dykes in Ibaraki.

\begin{tabular}{|l|c|c|c|}
\hline \multicolumn{1}{|c|}{ Index } & unit & Kujigawa clay & Jyouban clay \\
\hline \hline Void ratio $\mathrm{e}$ & & 2.17 & 2.40 \\
\hline Density of soil particle $\rho_{\mathrm{s}}$ & $\mathrm{g} / \mathrm{cm}^{3}$ & 2.67 & 2.68 \\
\hline Wet density $\rho_{\mathrm{t}}$ & $\mathrm{g} / \mathrm{cm}^{3}$ & 1.52 & - \\
\hline Natural water content $\mathrm{w}_{\mathrm{i}}$ & $\%$ & 81.0 & 93.7 \\
\hline Liquid limit $\mathrm{w}_{\mathrm{L}}$ & $\%$ & 73.0 & 70.7 \\
\hline Plasticity limit $\mathrm{w}_{\mathrm{L}}$ & $\%$ & 37.0 & 28.8 \\
\hline Plasticity index $\mathrm{I}_{\mathrm{p}}$ & & 36.0 & 41.9 \\
\hline Liquidity index $\mathrm{I}_{\mathrm{L}}$ & & 1.20 & 1.20 \\
\hline Sensitivity ratio $\mathrm{S}_{\mathrm{t}}$ & & 17.0 & 15.0 \\
\hline $\begin{array}{l}\text { Unconfined compression } \\
\text { strength } \mathrm{q}_{\mathrm{u}}\end{array}$ & $\mathrm{kN} / \mathrm{m}^{2}$ & 90.9 & 70.5 \\
\hline
\end{tabular}

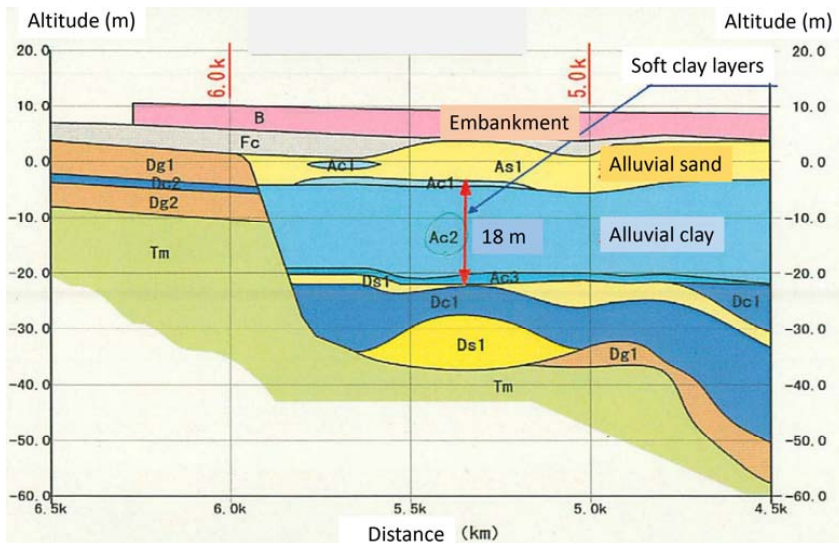

Figure 4. Geological profile of the objective site.

uid limit, although it cannot be said that the water content of either clay is very high.

A set of typical observed settlement vs. time relations continuously before and after the earthquake is presented in Fig. 5. Settlement before the earthquake is caused mainly by land subsidence because of ground water abstraction. However, settlement after the earthquake is very complex but perhaps caused by combining the following:

i. land sinking by crustal movement,

ii. immediate settlement followed by liquefaction of upper sand deposits, which is not time-dependent, and

iii. time-dependent settlement of clay followed by dissipation of excess pore pressure generated by earthquakes.

Those two components are present in addition to land subsidence.

The current paper, however, addresses issue (iii) because it emphasizes an examination of post-earthquake timedependent settlement of clay deposits, which corresponds to the latter part of the settlement vs. time curves depicted in Fig. 6. The rates of settlement before and after the earthquake are quite noticeable. The settlement has been exacer- 


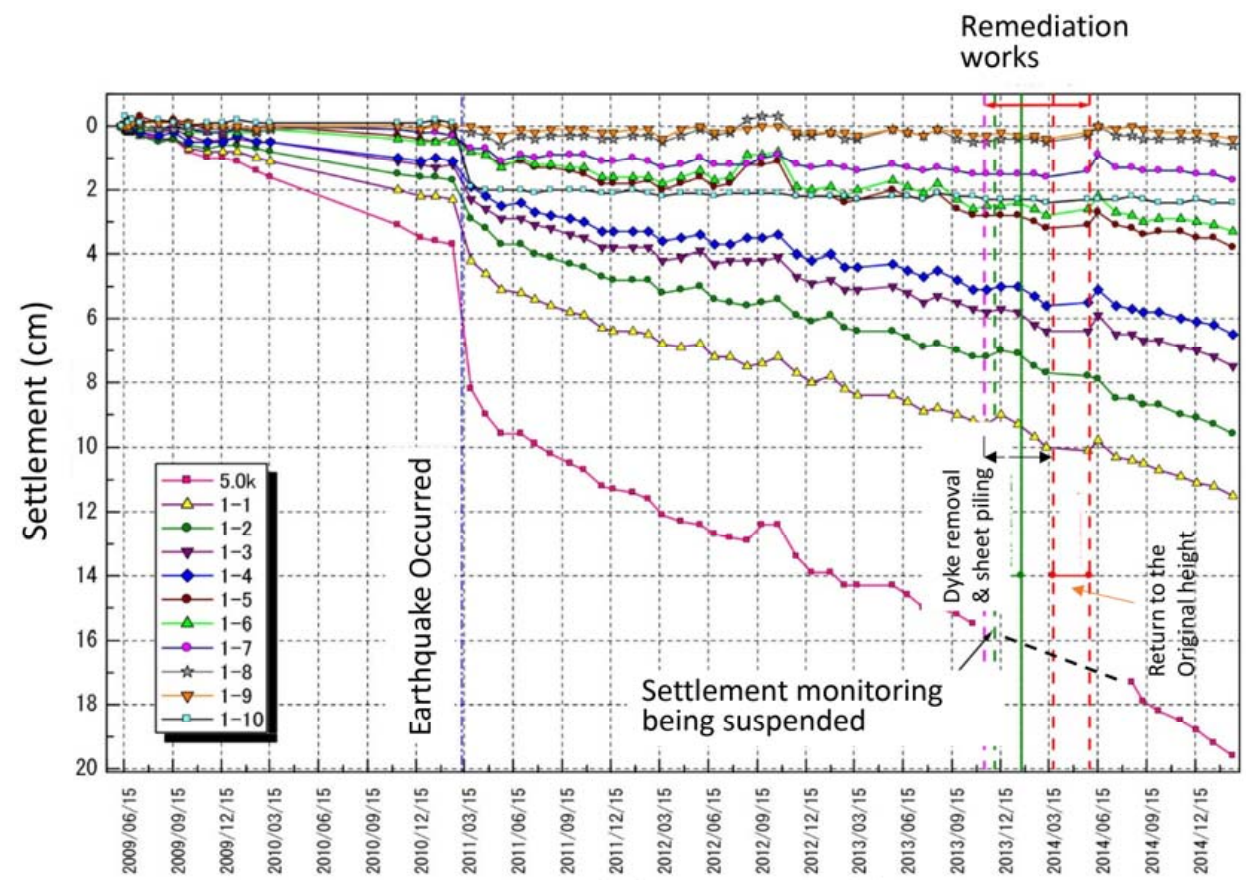

Figure 5. Settlement vs. time curves of river dykes.

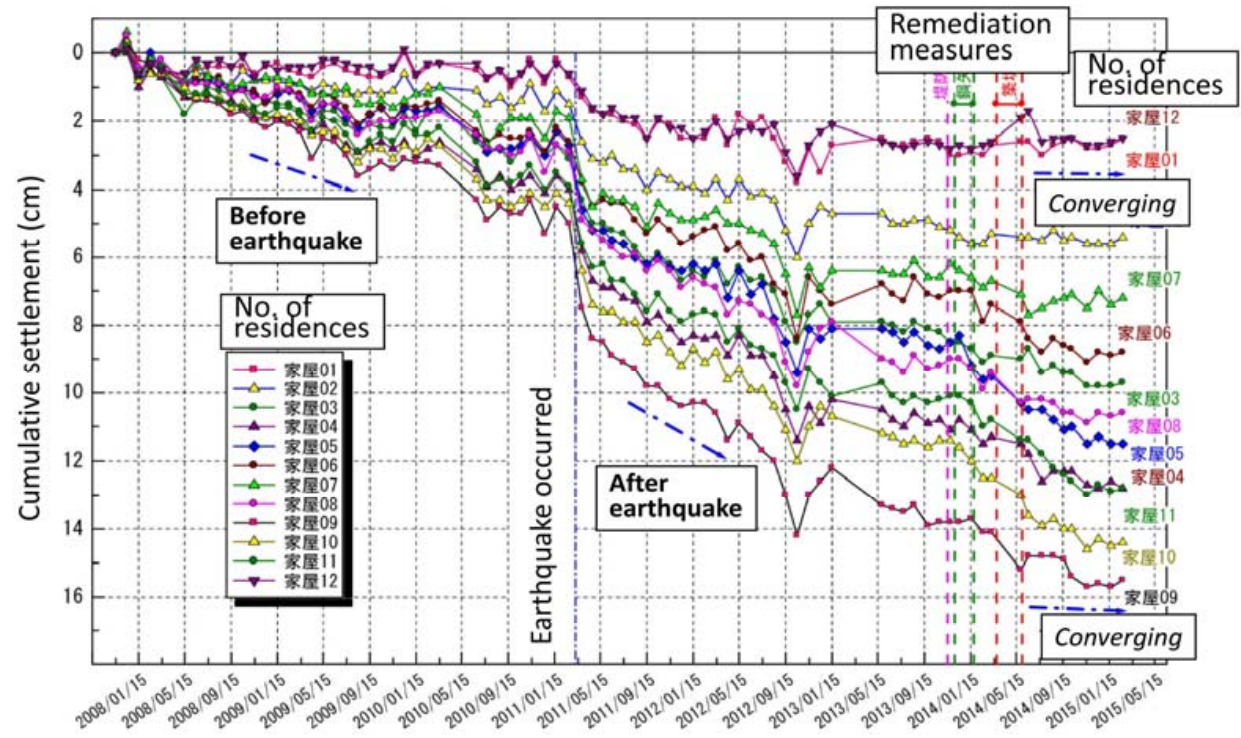

Figure 6. Settlement vs. time curves for residences.

bated by earthquakes because of the post-earthquake settlement of clay deposits caused by delayed dissipation of excess pore pressure in clay deposits after the earthquake. Generally speaking, such settlement takes a long time to cease. Therefore, it is necessary for engineers and researchers to ascertain when the rate of residual settlement after the earthquake becomes negligible for residents not to feel at risk in everyday life.

\subsection{Results from settlement monitoring and numerical analysis}

Since 2007, the Governmental Office in charge of river management in the objective area has been monitoring variations of settlement with time inside and outside the river dykes. Results of settlement monitoring indicate the following:

i. Settlement of residences accumulated up to $14 \mathrm{~cm}$ for the prior six years starting in 2007. 


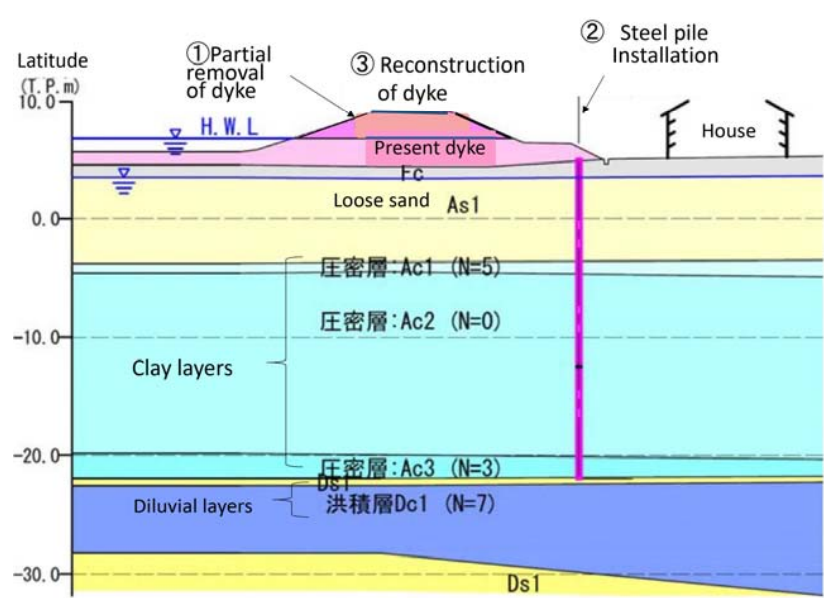

Figure 7. Remediation for reducing post-earthquake settlement of soft clay deposits.

ii. Settlement increased to around $2 \mathrm{~cm}$ after the earthquake in 2011.

According to elasto-visco-plastic two-dimensional numerical analysis for settlement of river dykes and residences conducted in addition to settlement monitoring:

i. The predicted total settlement of river dykes will be greater than $90 \mathrm{~cm}$.

ii. Settlement must persist for more than 30 years.

iii. Inclination of residences also continues for a long time.

\section{Effects of damage mitigation countermeasures}

To prevent the effects of river dykes on post-earthquake settlement of residences, the following countermeasures were undertaken (see Fig. 7).

i. Remove $2.2 \mathrm{~m}$ of dykes to reduce dyke self-weight.

ii. Thereafter install sheet piles aside from the river dykes into the hard stratus, called $\mathrm{A}_{c 3}$ layers, to intercept the effects of river dyke self-weight on residences.

iii. Return the dyke height to the original height with $4.1 \mathrm{~m}$.

As might be readily apparent from the results depicted in Figs. 5 and 6, the following behavior was observed after carrying out the countermeasures stated above.

i. Remaining excess pore pressure on grounds both outside and inside the dykes became less than that before partial removal of dykes.

ii. Installation of sheet piles is associated with increased ground settlements beneath the dykes, but does not increase settlement of the ground outside the dykes, but rather might decrease settlement of the ground of residents. iii. Filling up to the original height of dykes decreased settlement of the ground of residents because of the intercept of stress distribution of dykes to residential ground.

As a summary of the tendencies stated above, probably the countermeasures adopted herein have been effective to date for reducing post-earthquake settlement of residents near the river dykes. However, monitoring of settlements should be conducted because the influence of groundwater abstraction on continuous settlement of residential areas remains uncertain.

\section{Conclusion}

The paper presents an outline of the present situation of ground sinking, land subsidence, and settlement induced by tectonic movements on a global scale and ground movements on a local scale induced by the Tohoku Earthquake in 2011. Particularly, the paper describes a specific examination of post-earthquake settlement of clay layers observed in some locations in the Tohoku and Kanto regions. This paper describes two case histories related to this category of settlement: One in Miyagi for a methodology for predicting settlement and another in Ibaraki for effective countermeasures for settlement. Investigation of the two case histories suggests that careful attention should be devoted to the fact that such settlement is time-dependent and that monitoring of settlement should therefore continue for a long period. These phenomena show different tendencies from those of two kinds of settlement originating from tectonic movement, followed by liquefaction.

Acknowledgements. The authors are grateful for financial support from a Grant-in-Aid for Scientific Research from the Ministry of Education, Culture, Sports, Science and Technology (FY2014FY2017, Project No. 26281055), Japan, whose representative is Makoto Tamura, Associate Professor of Ibaraki University, Japan.

\section{References}

Imakiire, T. and Koarai, M.: Wide-area land subsidence caused by "the 2011 OFF the Pacific Coast of Tohoku Earthquake", Soils Found., 52, 842-855, 2012.

Joint Editorial Committee in Tohoku Branch for the Report on the Great East Japan Earthquake Disaster 2013, Part 3 Geohazards, Ch. 8, Land sinking and inundation, 3-212-3-218, 2013 (in Japanese).

Kazama, M.: Geotechnical subjects seen to the damage of the 2011 off the Pacific Coast of Tohoku Earthquake, Proc. 11th Symp. on Ground Improvement, Journal of Material Science, Japan, 1-20, 2014 (in Japanese).

Matsuda, H., Nhan, T. T., Nakahara, D., Thien, D. Q., and Tuyen, T. H.: Post-cyclic recompression characteristics of a clay subjected to undrained uniOdirectional and multi-directional cyclic shears, Proc. 10th US National Conf. on Earthquake Engineering, Earthquake Eng. Research Institute, Anchorage, AK, 2014. 
Ohara, S. and Matsuda, H.: Study on the settlement of saturated clay layer induced by cyclic shear, Soils Found., 28, 103-113, 1988.

Yasuhara, K. and Andersen, K. H.: Recompression of normally consolidated clay after cyclic loading, Soils Found., J. JGS, 31, 8394, 1991.

Yasuhara, K. and Matsuda, H.: 5. Dynamic properties of cohesive soils, J. of Japan Geotechnical Society, 46, 59-64, 1998 (in Japanese).
Yasuhara, K. and Usui, T.: Potential application of geosynthetics for reconstruction following coastal land subsidence induced by the Great East Japan Earthquake, Geosynthetics Journal, Japan Chapter of IGS, 27, 69-77, 2012 (in Japanese).

Yasuhara, K., Murakami, S., Toyota, N. and Hyde, A. F. L.: Settlements in fine-grained soils under cyclic loading, Soils Found., J. of JGS, 41, 25-36, 2001. 